\title{
Effect of dihydro-artemisinin on the pharmacokinetics of gliclazide in diabetic subjects
}

\author{
Sambo Godwin ISHAKU ${ }^{1,2^{*}}$, Mojirade Taibat BAKARE-ODUNOLA ${ }^{3}$, Aminu MUSA $^{1}$, \\ Ibrahim Adamu YAKASAI ${ }^{1}$, Magaji GARBA ${ }^{1}$ and Bulus ADZU ${ }^{4}$ \\ ${ }^{1}$ World Health Organization, Kaduna State Office, Kaduna, Nigeria. \\ ${ }^{2}$ Department of Pharmaceutical and Medicinal Chemistry, Faculty of Pharmaceutical Sciences, Ahmadu Bello \\ University, Zaria, Nigeria. \\ ${ }^{3}$ Department of Pharmaceutical and Medicinal Chemistry, Faculty of Pharmaceutical Sciences, University of \\ Ilorin, Nigeria. \\ ${ }^{4}$ Department of Pharmacology and Toxicology, National Institute for Pharmaceutical Research and \\ Development, Abuja, Nigeria. \\ *Corresponding author; E-mail: samboishaku@yahoo.com; Tel: +2348033489096.
}

\begin{abstract}
Diabetic patients do have co-occurring diseases like malaria, especially in tropical regions. Hence, polypharmacy is sometimes unavoidable. Gliclazide is widely used in the treatment of non-insulin-dependent type 2 diabetes mellitus, while dihydro-artemisinin (DHA) is one of the most promising medications used in the treatment of malaria on account of its good efficacy and tolerability. The study evaluated the effect of DHA on the pharmacokinetics of gliclazide in diabetic patients. This is a single dose one-way, cross-over study in two periods, with each phase preceded by an overnight fast. Six subjects that passed inclusion criteria participated in the study. The volunteers acted as their control. Phase 1 of the study involved administering a single oral dose of $80 \mathrm{mg}$ of gliclazide after an overnight fast. After a washout period of one week, $80 \mathrm{mg}$ gliclazide and $120 \mathrm{mg}$ DHA were co-administered. Serial blood samples were collected at time intervals throughout $24 \mathrm{~h}$ and processed. A validated HPLC method was used to estimate serum gliclazide concentration, while the glucose oxidase peroxidase method was used in the evaluation of blood glucose concentration. The Pharmacokinetic Software PharmPK was used to generate the pharmacokinetic parameters. GraphPad Prism version 7.01 software for window was used for data analysis. Statistical differences observed in the pharmacokinetic profiles of gliclazide and blood glucose concentration were not significant. Single oral dose of gliclazide and dihydro-artemisinin had good safety and tolerability in diabetic subjects.
\end{abstract}

(C) 2020 International Formulae Group. All rights reserved.

Keywords: Diabetes mellitus, Dihydro-artemisinin, Drug Interactions, Gliclazide, Pharmacokinetics.

\section{INTRODUCTION}

Diabetes mellitus (DM), a group of diseases with a variety of causes due to the disorder of metabolism, is characterized by high blood glucose levels (WHO 2016; CDC, 2017). Over time, this damages nerves and blood vessels, leading to complications such as heart disease, blindness, stroke, dental diseases, kidney disease, and amputations. DM has other complications, including increased susceptibility to other diseases, loss of mobility with aging, depression, and pregnancy 
problems (CDC, 2017). The condition can cause pathophysiological changes in the body that include a reduction in gastric emptying time, albumin glycation, and CYP activity; that affect the pharmacokinetics and pharmacodynamics of drugs (Stachowiak et al., 2019).

Diabetes mellitus is mainly of 2 types: type 1 (insulin-dependent). It is usually first diagnosed in children, teenagers and young adults, and type 2 (non-insulin dependent) often related to old age-gestational diabetes associated with pregnancy. Gliclazide plays a vital role in the treatment of type 2 diabetes mellitus (Yang et al., 2018). It helps improve insulin secretion in the body by blocking $\mathrm{K}^{+}$ channels in the pancreatic $\beta$ cells and increasing tissue uptake of glucose (Sandoz Product Monograph, 2018) and inhibition of vascular smooth muscle cell proliferation through the CaMKK $\beta$-AMPK pathway (Lee et al., 2018).

Artemisinin Combination Therapies (ACTs) are currently the frontline treatment of uncomplicated /multidrug-resistant $P$. falciparum malaria. They produce rapid and profound reductions/elimination of parasitemia. Dihydro-artemisinin based combinations remain one of the most-likely, on account of its good efficacy and tolerability (Hasugian et al., 2007; Millat-Martinez et al., 2018). Diabetic patients do have comorbidities with malaria infestation, especially in tropical regions. In such malarial endemic areas, the need for polypharmacy for most diabetic patients becomes evident in most patients (Greenblatt et al., 2017) and sometimes unavoidable for such patients, thereby increasing the likelihood of drug-drug interactions. It has been known that polypharmacy is a risk factor in the treatment of diabetes (Austin, 2006), which requires proper care and better quality of drugs (Ribeiro da Silva, 2018). Some studies showed $91.2 \%$ of diabetic patients have comorbidities (Geitona et al., 2017); hence, polypharmacy is sometimes unavoidable for such patients (ALmohamadi and Ibrahim, 2015). The fact is that it is a growing phenomenon (Pinnamraju et al.,
2018) and shared in diabetic patients (ALmohamadi and Ibrahim, 2015) hence complicating diabetes management (Peron et al., 2015). The study of drug-drug interactions becomes vital to ascertain the safety and efficacy of such drugs (Mandlem et al., 2014).

Several studies have confirmed the influence of diabetes mellitus on the pharmacokinetics of drugs (Stachowiak et al., 2019). Since maintenance of normal blood glucose levels is essential in diabetes monitoring of anti-diabetic drug therapy in the presence of other drugs, the influence of such drugs needs to be evaluated to maintain safety (Kilari et al., 2012). Recently, we started testing common antimalarials on the pharmacokinetics of gliclazide in diabetic subjects to assess their safe and efficacious use. Part 1 of the study was on amodiaquine (Ishaku et al. 2019a), while Part 2 was on artesunate (Ishaku et al., 2019b). In this continuation, the study evaluated the effect of dihydroartemisinin on the pharmacokinetics of gliclazide in diabetic subjects.

\section{MATERIALS AND METHODS}

\section{Subjects and ethical clearance}

The diagnosis of diabetes mellitus was established at the medical outpatient department of Barau-Dikko Teaching Hospital in Kaduna, Nigeria. Kaduna State Ministry of Health Ethical Committee approved this study (approval number MOH/ADM/744/T/17, dated 28 January 2010) per the National Code of Health Research Ethics (2006) under Federal Ministry of Health, Nigeria; and also, with the Helsinki declaration (1964) and its later amendments or comparable ethical standards. The study was carried between October 2011 and December 2011 at BarauDikko Teaching Hospital (formerly, BarauDikko Specialist Hospital), Kaduna. Written informed consent was obtained, documented, and archived.

\section{Inclusion/exclusion criteria}

Before the start of the study, a structured questionnaire was filled for each volunteer, which included medical history, 
clinical and laboratory data, and prior hospital admissions. Volunteers included for the study are freshly diagnosed patients who were on lifestyle modification, willingness to fill an informed consent form, non-smokers, which are not alcohol drinkers, and are willing to abstain from heavy exercise during the study period. They were not on other medications during the study, and have agreed to refrain from caffeine. The volunteer also met a Body Mass Index (BMI) of less than $30 \mathrm{~kg} / \mathrm{m}^{2}$. Subjects who are Pregnant and those currently undergoing any medication or planned treatment during the study period were excluded from the studies.

\section{Study design and blood sampling}

The protocol adopted was a cross-over, one-way single-dose study in two phases. Each phase followed an overnight fast. The subjects act as their control. The first phase of the study involved the administration of a single oral dose of $80 \mathrm{mg}$ of gliclazide after an overnight fast. After a washout period of one week, 80 $\mathrm{mg}$ gliclazide and $120 \mathrm{mg}$ DHA were concomitantly administered. Blood samples (5 $\mathrm{ml})$ were collected serially at intervals ranging from $0,0.5,1,2,4,6,8,12,16$, and $24 \mathrm{~h}$ during each phase into an EDTA vacutainer.

\section{Blood sample processing}

After collection, blood samples were centrifuged at $2000 \mathrm{rpm}$, and plasma kept frozen in a freezer maintained at $-20{ }^{\circ} \mathrm{C}$ after which, it was analyzed. For gliclazide to be extracted from the plasma, the frozen plasma was thawed and to $1.0 \mathrm{ml}$ of plasma was added $0.1 \mathrm{~mL}$ of glipizide (internal standard, 20 $\mu \mathrm{g} / \mathrm{ml}), 0.2 \mathrm{ml}$ of $0.4 \mathrm{~mol} / \mathrm{l}$ of $\mathrm{HCl}$, with $5.0 \mathrm{ml}$ of benzene- isopropanol $(98: 2, \mathrm{v} / \mathrm{v})$, and this was vortex-mixed for 2 minutes. This was followed by centrifugation of the mixed samples at $2000 \mathrm{rpm}$ for $5 \mathrm{~min}$, after which the upper layer $(4.0 \mathrm{ml})$ was placed into another tube and was dried in a hot air oven (Memmert 854 Schwalbach-Germany) at $40{ }^{\circ} \mathrm{C}$. Methanol $(0.15 \mathrm{ml})$ was used to resolve the dried residue, and $20 \mu \mathrm{l}$ of the solution was injected into the liquid chromatography.

\section{Determination of plasma gliclazide concentration}

A validated HPLC method (Yang et al. 2004) was used in the estimation of serum gliclazide concentration using an HPLC instrument (Shimadzu ${ }^{\circledR}$ chromatograph-LC-10 series, Japan) as earlier described (Ishaku et al. 2019a). The system used (Shimadzu Corporation, Kyoto Japan) consists of UltraFast LC-20AB prominence with the following accessories: UV-diode array detector; SPDM20ASIL-20AC auto-sampler; CTO-20AC column oven; DGU-20A3 degasser; $5 \mu \mathrm{m}$ VPODS $\mathrm{C}_{18}$ and dimensions $(4.6 \times 150 \mathrm{~mm})$; CBM-20Alite system controller and Windows software (LCsolution). The chromatographic set-up was made up of the mobile phase with solvent A, being water $(\mathrm{pH} 2.8) 51 \%$ and solvent B being acetonitrile 49\%; in the isocratic mode. The HPLC flow rate was 1 $\mathrm{ml} / \mathrm{min}$; injection volume of $20 \mu \mathrm{l}$, a detection wavelength, UV $229 \mathrm{~nm}$, and a Column oven temperature of $40{ }^{\circ} \mathrm{C}$. The internal standard used was glipizide, and the total run time was $7.5 \mathrm{~min}$.

\section{Determination of glucose concentration}

Glucose oxidase peroxidase method (Trinder, 1969) was used to determine plasma glucose concentration was measured throughout $24 \mathrm{~h}$ at 9-time point's interval. 10 $\mu \mathrm{l}$ of the plasma sample $\left(\mathrm{A}_{\text {sample }}\right)$ or standard ( $\left.\mathrm{A}_{\text {standard }}\right)$ was transferred into a microcentrifuge tube $(1.5 \mathrm{ml})$ which contained $1000 \mu \mathrm{l}$ of glucose reagent (Randox), and this was well mixed and incubated for at $20 \pm 5{ }^{\circ} \mathrm{C}$ for $10 \mathrm{~min}$. The mixture, which became slightly pink, was then transferred to a $1 \mathrm{~cm}$ path length cuvette, and the absorbance of the standard and sample was measured at $\lambda 500 \mathrm{~nm}$ against the $1000 \mu \mathrm{l}$ reagent blank within $30 \mathrm{~min}$. The equation below (Glucose Concentration (mmol/ L) $\left.=\frac{A(\text { sample })}{A \text { (standard })} X 5.5\right)$ was used to determine plasma glucose concentration during the two phases of the study and were compared. 


\section{Pharmacokinetic analysis}

The Non-compartmental method was used for Pharmacokinetic analysis using the Pharmacokinetic Software - PharmPK software (Joel et al. 2012). The following Pharmacokinetic parameters were generated: Maximum plasma concentration $\left(\mathrm{C}_{\max }\right)$, Time to maximum plasma concentration $\left(\mathrm{T}_{\max }\right)$, Total body clearance $(\mathrm{Cl})$, Volume of distribution (VD), Area under the curve from zero hours to last measurable concentration $\left(\mathrm{AUC}_{0-\mathrm{t}}\right.$ ), Area under the curve (from zero hours to infinity $\left(\mathrm{AUC}_{0-\infty}\right)$, Area under the Moment curve from zero hours to last measurable concentration (AUMC 0-t), Area under the Moment curve from zero hours to infinity $\left(\mathrm{AUMC}_{0-\infty}\right)$, Elimination half-life $\left(\mathrm{t}_{1 / 2 \mathrm{eli}}\right)$, Elimination rate constant $\left(\mathrm{K}_{\mathrm{eli}}\right)$. The method of residual was used to generate Absorption half-life ( $\left.\mathrm{t}^{1} / \mathrm{zabs}_{\mathrm{ab}}\right)$, Absorption rate constant ( $\mathrm{K}_{\mathrm{abs}}$ ) using Microsoft excel. Total body clearance $(\mathrm{Cl})$, the volume of distribution (VD), and Mean residence time (MRT).

\section{Data analysis}

Data were expressed as mean \pm SEM. GraphPad Prism Version 7.01 software for Windows (San Diego California, USA) was used for data analysis using Student's T-test with $p<0.05$ considered significant.

\section{RESULTS \\ Subjects}

Six freshly diagnosed diabetic subjects (two males and four females) on dietary and lifestyle modification met the inclusion criteria. Their mean age (years) was $53.8 \pm 0.962$, and the mean Body Mass Index (BMI) of $24.78 \pm 0.353$. All subjects completed the treatment periods and were included in the pharmacokinetic analysis.

\section{Plasma gliclazide concentration}

Table 1 showed the mean pharmacokinetic parameters generated after a single oral dose of $80 \mathrm{mg}$ of gliclazide alone and when used concomitantly with $120 \mathrm{mg}$ of DHA. Changes in the $\mathrm{C}_{\max }(95 \% \mathrm{CI}=-1.218$ to $\left.2.684 \mu \mathrm{g} / \mathrm{ml}, \mathrm{R}^{2}=0.1572\right), \mathrm{T}_{\max }(95 \% \mathrm{CI}=-$
2.794 to $\left.5.461 \mathrm{~h}, \mathrm{R}^{2}=0.1212\right), \mathrm{T}^{1 / 2} \mathrm{abs}(95 \% \mathrm{CI}=-$ 1.261 to $\left.1.228 \mathrm{~h}, \mathrm{R}^{2}=0.0002318\right), \mathrm{K}_{\text {abs }}(95 \%$ $\mathrm{CI}=-0.8243$ to $\left.0.5952 \mathrm{~h}^{-1}, \mathrm{R}^{2}=0.03327\right) \mathrm{AUC}_{0-}$ t(95\% CI=-10.24 to $20.97 \mu \mathrm{g} . \mathrm{h} / \mathrm{ml}$, $\left.\mathrm{R}^{2}=0.1351\right) \mathrm{AUC}_{0 \text {-inf }}(95 \% \mathrm{CI}=-9.027$ to 22.46 $\left.\mu \mathrm{g} . \mathrm{h} / \mathrm{ml}, \mathrm{R}^{2}=0.194\right) \mathrm{AUMC}_{0-\mathrm{t}}(95 \% \mathrm{CI}=-63.74$ to $205.1 \mu \mathrm{g} . \mathrm{h}^{2} / \mathrm{ml}, \mathrm{R}^{2}=0.2676$ ) were observed. Although there is a difference in the values between the control and co-administer phase, all the pharmacokinetic parameters generated were not significantly altered $(p>0.05)$ clearly denoting a lack of significant pharmacokinetic interactions between gliclazide and dihydroartemisinin (Figure 1).

Changes in the MRT (95\% CI=-22.21 to $\left.14.49 \mathrm{~h}, \mathrm{R}^{2}=0.05523\right), \mathrm{Cl}(95 \% \mathrm{CI}=-1786$ to $\left.175.8 \mathrm{ml} / \mathrm{h}, \mathrm{R}^{2}=0.471\right) \mathrm{K}_{\text {eli }}(95 \% \mathrm{CI}=-0.03678$ to $\left.0.06555 / \mathrm{h}, \mathrm{R}^{2}=0.09457\right) \mathrm{T}^{1} / 2$ eli $(95 \% \mathrm{CI}=-$ 3.902 to $\left.2.701 \mathrm{~h}, \mathrm{R}^{2}=0.04187\right)$ were not statistically significant $(p>0.05)$ for these parameters. The data shows that the metabolism and elimination of Gliclazide were not significantly affected by the presence of DHA.

The concentration versus time profile of gliclazide when administered alone, and in the presence of DHA, is shown in Figure 1. For the control, there was a gradual increase in mean gliclazide concentration from zero $\mathrm{h}$ to a maximum at $4.33 \mathrm{~h}$ then a gradual decrease at the $C_{\max }(\mu \mathrm{g} / \mathrm{ml})$, with a range of 1.4085 $5.0959 \mathrm{ug} / \mathrm{ml}$; whereas for the coadministration of gliclazide with DHA, there was a $C_{\max }(\mu \mathrm{g} / \mathrm{ml})$ range of $2.0196-4.9836$.

\section{Glucose concentrations}

The mean plasma glucose concentration is given in Table 2. There was a minimal increase in plasma glucose concentration between $0.5 \mathrm{~h}-8 \mathrm{~h}$ ranging from between 3 and $12 \%$, while a decrease in blood glucose concentration was observed between 12 and 24 $\mathrm{h}$ ranging from between 8 and 20\%. These observed changes were not significant $(p>0.05)$. There was a concordance between the maximal plasma concentration of gliclazide and the maximum decrease in plasma glucose concentration (Figure 2). 
Table 1: Mean Pharmacokinetic parameters of Gliclazide ( $n=6)$.

\begin{tabular}{|c|c|c|c|c|c|c|}
\hline & \multicolumn{2}{|c|}{$\begin{array}{c}\text { Control (Gliclazide } \\
\text { alone) }\end{array}$} & \multicolumn{2}{|c|}{$\begin{array}{c}\text { Gliclazide+Dihydro- } \\
\text { Artemisinin }\end{array}$} & \multicolumn{2}{|c|}{ The T-Test (paired value) } \\
\hline & Mean & $\operatorname{SEM}( \pm)$ & Mean & $\operatorname{SEM}( \pm)$ & (P-Value) & \\
\hline $\mathrm{C}_{\max }(\mu \mathrm{g} / \mathrm{ml})$ & 2.989 & 0.201 & 3.722 & 0.168 & $p>0.05$ & $(p=0.3785)$ \\
\hline $\mathrm{T}_{\max }(\mathrm{h})$ & 4.333 & 0.234 & 5.667 & 0.272 & $p>0.05$ & $(p=0.4441)$ \\
\hline $\mathrm{K}_{\mathrm{eli}}\left(\mathrm{h}^{-1}\right)$ & 0.099 & 0.030 & 0.113 & 0.033 & $p>0.05$ & $(p=0.5023)$ \\
\hline $\mathrm{T}^{1} / 2$ eli (h) & 7.633 & 0.257 & 7.033 & 0.297 & $p>0.05$ & $(p=0.6598)$ \\
\hline $\mathrm{AUC}_{0-\mathrm{t}}(\mu \mathrm{g} \cdot \mathrm{h} / \mathrm{ml})$ & 31.085 & 0.656 & 36.451 & 0.495 & $p>0.05$ & $(p=0.4173)$ \\
\hline $\mathrm{AUC}_{0 \text {-inf }}(\mu \mathrm{g} \cdot \mathrm{h} / \mathrm{ml})$ & 36.059 & 0.805 & 42.778 & 0.591 & $p>0.05$ & $(p=0.3227)$ \\
\hline $\operatorname{AUMC}_{O-t}\left(\mu \mathrm{g} \cdot \mathrm{h}^{2} / \mathrm{ml}\right)$ & 261.183 & 2.019 & 331.867 & 1.775 & $p>0.05$ & $(p=0.2344)$ \\
\hline $\operatorname{AUMC}_{0-\text { inf }}\left(\mu \mathrm{g} \cdot \mathrm{h}^{2} / \mathrm{ml}\right)$ & 441.871 & 2.989 & 506.731 & 3.355 & $p>0.05$ & $(p=0.7092)$ \\
\hline MRT (h) & 14.698 & 0.646 & 10.839 & 0.456 & $p>0.05$ & $(p=0.6120)$ \\
\hline $\mathrm{Cl}\left(\mathrm{mlh}^{-1}\right)$ & 2806.956 & 6.969 & 2001.722 & 4.686 & $p>0.05$ & $(p=0.0886)$ \\
\hline $\mathrm{VD}(\mathrm{ml})$ & 28993.417 & 22.289 & 19561.494 & 17.986 & $p>0.05$ & $(p=0.2572)$ \\
\hline $\mathrm{T}^{1} 1 / 2$ abs $(\mathrm{h})$ & 1.704 & 0.201 & 1.687 & 0.212 & $p>0.05$ & $(p=0.9742)$ \\
\hline $\mathrm{K}_{\mathrm{abs}}\left(\mathrm{h}^{-1}\right)$ & 0.663 & 0.157 & 0.548 & 0.155 & $p>0.05$ & $(p=0.6955)$ \\
\hline
\end{tabular}

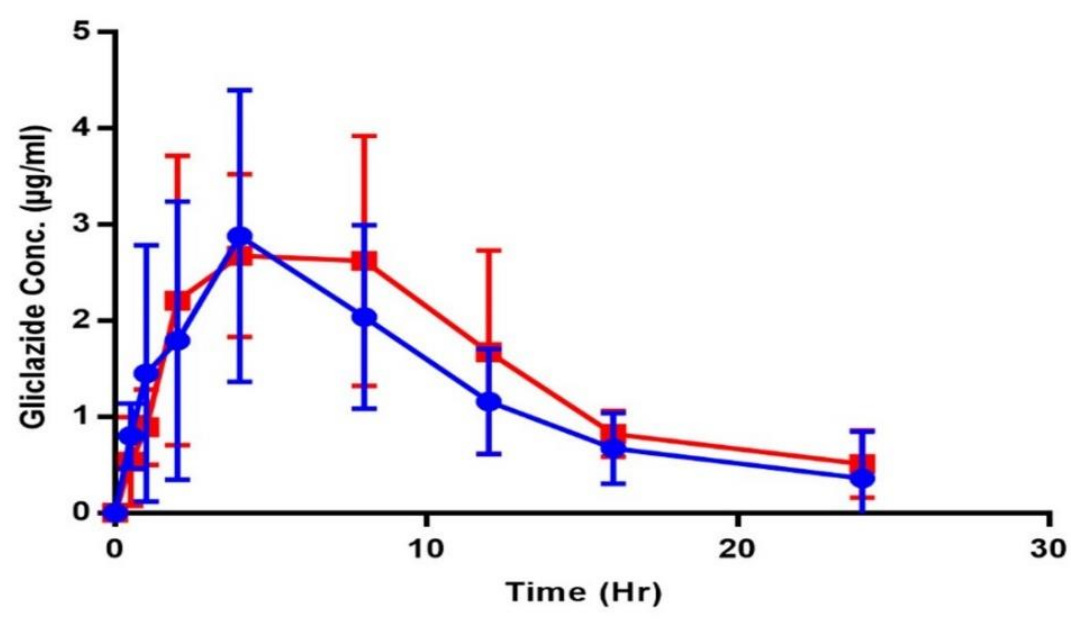

Control (Gliclazide Alone)

Gliclazide Co-administered vith Dihydro-artemisinin

Figure 1: Mean plasma gliclazide concentration-time profile. 
Table 2: Blood glucose concentration ( $\mathrm{mmol} / \mathrm{l})$.

\begin{tabular}{|c|c|c|c|c|c|c|}
\hline \multirow[b]{2}{*}{ Time (h) } & \multicolumn{3}{|c|}{ Control (Gliclazide alone) } & \multicolumn{2}{|c|}{ Gliclazide+DHA } & \multirow[t]{2}{*}{ T-Test } \\
\hline & Mean & $\operatorname{SEM}( \pm)$ & Mean 2 & SEM $( \pm)$ & & \\
\hline 0 & 8.201 & 0.185 & 7.914 & 0.245 & $p>0.05$ & $(p=0.8039)$ \\
\hline 0.5 & 7.683 & 0.250 & 7.938 & 0.281 & $p>0.05$ & $(p=0.8773)$ \\
\hline 1 & 7.117 & 0.251 & 7.832 & 0.253 & $p>0.05$ & $(p=0.6449)$ \\
\hline 2 & 6.612 & 0.216 & 7.388 & 0.244 & $p>0.05$ & $(p=0.5397)$ \\
\hline 4 & 5.797 & 0.201 & 6.016 & 0.211 & $p>0.05$ & $(p=0.8332)$ \\
\hline 8 & 5.897 & 0.280 & 6.045 & 0.305 & $p>0.05$ & $(p=0.9519)$ \\
\hline 12 & 8.918 & 0.237 & 7.134 & 0.185 & $p>0.05$ & $(p=0.1230)$ \\
\hline 16 & 10.249 & 0.197 & 8.985 & 0.274 & $p>0.05$ & $(p=0.4140)$ \\
\hline 24 & 10.088 & 0.289 & 9.316 & 0.254 & $p>0.05$ & $(p=0.6725)$ \\
\hline
\end{tabular}

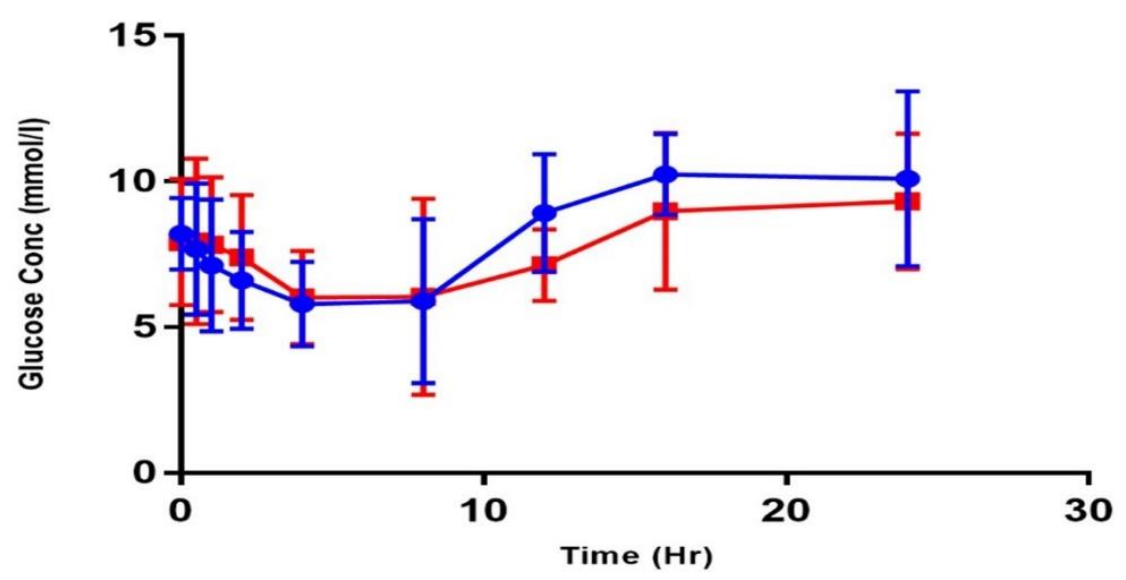

Control (Gliclazide Alone)

Gliclazide Co-administered vith Dihydro-artemisinin

Figure 2: Mean plasma glucose concentration-time profile. 


\section{DISCUSSION}

The influence of diabetes on drug metabolism in polypharmacy has not been thoroughly investigated even though it is a growing phenomenon (Pinnamraju et al., 2018) and shared in diabetic patients (AL-mohamadi et al., 2015). This study's objective was to evaluate $120 \mathrm{mg}$ of DHA with a coadministered with $80 \mathrm{mg}$ gliclazide in diabetic subjects. Freshly diagnosed diabetes subjects which were not yet placed on treatment but were on diet and exercise participated in the study; this is to preclude the need for simultaneous drug intake during the course of the study. For this work, the differences in pharmacokinetic parameters of gliclazide and plasma glucose level for both phases of the study were studied. Healthy volunteers as a study group were not used in the study for comparison purposes; hence the effect of disease state on the pharmacokinetics of gliclazide might be a potential source of bias.

The pharmacokinetic and pharmacodynamic interactions of gliclazide with several drugs have been reported. Drugs like rifampicin affect the disposition of gliclazide in humans, with both pharmacokinetics and pharmacodynamics implications (Park et al., 2003). Other drugs for which there are significant interactions with gliclazide are efavirenz (AL-mohamadi et al., 2015), St. John's wort (Xu et al., 2008), Ayuslim herbal drug (Mandlem et al., 2014) and capsaicin (Lagisetty et al., 2018). However, some studies showed a lack of interactions with gliclazide (Delrat et al., 2002), among others. In light of this information, it becomes essential to ascertain the pharmacokinetic interactions of Gliclazide with drugs that are commonly co-administered like the antimalarials.

As shown in the result, all the pharmacokinetic parameters generated were not significantly altered $(p>0.05)$, clearly denoting a lack of significant pharmacokinetic interactions between gliclazide and DHA. Changes in clearance and elimination half-life were not statistically significant $(p>0.05)$. This data shows that the metabolism and elimination of Gliclazide were not significantly affected by the presence of dihydroartemisinin. A change in the clearance, MRT and elimination half-life has implications for the duration of action of the drug in the body (Triplitt, 2006). A mean low volume of distribution of $28 \mathrm{~L}$ was generated for gliclazide when administered alone, consistent with the literature. Drugs, having this low volume of distribution as with gliclazide, which is reported to have a protein binding up to $84-99 \%$ (Campbell et al., 1991), is highly protein-bound. A drug interaction that affects protein binding affects the distribution of the drug in the system. Displacement from the binding site may lead to increase concentration and or increase in therapeutic effect or toxicity depending on the therapeutic index of the drug (Triplitt, 2006). One drug can displace another from the binding sites on the plasma proteins if the binding is more durable. Changes observed in the volume of distribution were not significant $(p>0.05)$. However, the data showed that the displacement of gliclazide from protein binding sites by dihydroartemisinin could not be concluded. No significant distribution interactions are pertinent for oral medications commonly used for diabetes (Benet and Hoener, 2002).

To complement the pharmacokinetic data, the pharmacodynamics of gliclazide was assessed in terms of glucose concentration. Plasma glucose concentration was measured throughout $24 \mathrm{~h}$ at nine interval time points. In the plasma glucose concentration for all time points between the two phases of the study were compared. There was a minimal increase in plasma glucose concentration between 3 and $12 \%$ at $0.5 \mathrm{~h}$ to $8 \mathrm{~h}$, and a $20 \%$ decrease in blood glucose concentration observed between 12 and $24 \mathrm{~h}$. These changes were, however, not significant $(\mathrm{p}>0.05)$, and there was concordance between maximal plasma concentration of gliclazide and the maximum decrease in plasma glucose concentration (Figure 2). Thus, pharmacodynamic findings were in agreement with pharmacokinetic results. Blood glucose concentration was seen to increase gradually after the maximum 
reduction. This might indicate the presence of fasting hyperglycemia that could lead to the worsening of diabetes state in the studied patients. It is possible that the subjects have had diabetes for a long time before diagnosis.

\section{Conclusion}

These findings showed that administering a single oral dose of gliclazide and dihydro-artemisinin did not alter gliclazide's disposition in diabetic subjects. A study after a multiple-dose administration of these drugs is suggested to see if similar effects can be observed.

\section{COMPETING INTERESTS}

The authors have no relevant conflict of interest. For this study and publication, no funding was received

\section{AUTHORS CONTRIBUTIONS}

SGI, MTB, AM, IAY, MG, designed the study; SGI collected samples; SGI and BA performed the experiment, analyzed result and wrote the draft of the manuscript. All authors read and made input to the final draft. The authors declare that all data were generated inhouse and that no paper mill was used.

\section{ACKNOWLEDGEMENTS}

This work is part of a Ph.D. dissertation presented to the Department of Medicinal and Pharmaceutical Chemistry, Ahmadu Bello University, Zaria by S.G Ishaku. The authors are appreciative of the volunteers for participating in the study. They are thankful to Mr. Emmanuel Christopher (Phlebotomist) of Barau-Dikko Teaching Hospital-Kaduna, Mal. Iliya Salisu (Chief Laboratory Technologist) of the Department of Pharmaceutical and Medicinal Chemistry, Ahmadu Bello University, Zaria, Nigeria; Dr. Samuel E. Okhale of the Department of Medicinal Plant Research and Traditional medicine, National Institute for Pharmaceutical Research and development, Abuja, Nigeria; and the management of Barau-Dikko Teaching Hospital, Kaduna for permitting the use of their facilities for the study.

\section{ETHICAL CONSIDERATION}

The procedures performed in studies were as per the National Code of Health Research Ethics (2006), Federal Ministry of Health, Nigeria), and with the Declaration of Helsinki and good clinical practice guidelines. The health ethics committee of Kaduna State Ministry of Health (approval number $\mathrm{MOH} / \mathrm{ADM} / 744 / \mathrm{T} / 17$, dated 28 January 2010).

All subjects provided written informed consent before participation.

\section{REFERENCES}

AL-mohamadi AA, Ibrahim DA. 2015. Possible Study of Drug-Drug Interactions between Lisinopril and Gliclazide in Experimental Animals. J. Drug Discovery Ther., 3(33): 04-12. http://jddt.in/index.php/jddt/article/view/ 344

Austin RP. 2006. Polypharmacy as a Risk Factor in the Treatment of Type 2 Diabetes. Diabetes Spectrum, 19(1): 1316 DOI: https://doi.org/10.2337/diaspect.19.1.13

Benet LZ, Hoener BA. 2002. Changes in plasma protein binding have little clinical relevance. Clin. Pharmacol. Ther., 71: 115-121. DOI: $10.1067 / \mathrm{mcp} .2002 .121829$

Campbell DB, Lavielle R, Nathan C. 1991. The mode of action and clinical pharmacology of Gliclazide: a review. Diabetes Res. Clin. Pract., 14: S21-S36.

Center for Disease Control and Prevention. National Diabetes Statistics Report. 2017. http://www.cdc.gov/diabetes/index.htm (Accessed, 29 December 2018).

Delrat P, Paraire M, Jochemsen R. 2002. Complete bioavailability and lack of food-effect on the pharmacokinetics of Gliclazide $30 \mathrm{mg}$ modified-release in healthy volunteers. Biopharm Drug Dispos., 23(4): 151-157. DOI: 10.1002/bdd.303

Geitona M, Latsou D, Markou E, Michou I, Pitelis P, Papafili G, Toska A, Saridi M. 2017. Factors Affecting Polypharmacy in 
Elderly Patients with Diabetes in Greece. Value Health., 20(9): A487.

Greenblatt DJ, von Moltke LL. Harmatz JS, Shader RI. 2017. Pharmacokinetics, Pharmacodynamics, and drug disposition. https://acnp.org/wp-

content/uploads/2017/11/ CH38_507524.pdf

Hasugian AR, Purba HLE, Kenangalem E, Wuwung RM, Ebsworth EP, Maristela R, Penttinen PMP, Laihad F, Anstey NM, Tjitra E, Price RN. 2007. Dihydroartemisinin-Piperaquine versus Artesunate-Amodiaquine: Superior Efficacy and Posttreatment Prophylaxis against Multidrug-Resistant Plasmodium falciparum and Plasmodium vivax malaria. Clin. Infect. Dis., 44(8): 10671074. DOI: $10.1086 / 512677$.

Ishaku SG, Bakare-Odunola MT, Musa A, Yakasai IA, Garba M, Adzu B. 2019a. Effect of amodiaquine on the pharmacokinetics of Gliclazide in diabetic subjects. Afr. J. Pharm. Pharmacol., 13(11): 139 - 145. DOI: 10.5897/AJPP2019.5035

Ishaku SG, Bakare-Odunola, MT, Musa A, Yakasai IA, Garba M, Adzu B. 2019b. Evaluating the effect of artesunate on the pharmacokinetics of Gliclazide in diabetic subjects. Int. J. Biol. Chem. Sci., 13(4): 2104-2111. DOI: https://dx.doi.org/10.4314/ijbcs.v13i4.17

Joel IU, Atul D, Diane TL. 2012. PK Function on Microsoft excel. Department of pharmacokinetics and drug Metabolism. Allergen, Irvine, CA 92606. The USA.

Kilari EK, Raghu RK, Swathi P, Jyotsna Rani P, Gupta MN. 2012. Pharmacodynamic and pharmacokinetic drug interaction of Gliclazide and olanzapine in animal models. IOSR J. Pharm., 1(1):035-043.

Lagisetty U, Mohammed H, Ramaiah S. 2018. Effect of capsaicin on pharmacodynamic and pharmacokinetics of Gliclazide in animal models with diabetes. Pharmacogn. Res., 10(4):437-441. DOI: $10.4103 /$ pr.pr_81_18
Lee KY, Jae-Kim, JR, Choi AC. 2018. Gliclazide, a K ATP channel blocker, inhibits vascular smooth muscle cell proliferation through the CaMKK $\beta$ AMPK pathway. Vasc. Pharmacol., 102: 21-28. DOI: 10.1016/j.vph.2018.01.001

Mandlem KK, Kilari EK, Pingili RB. 2014. Influence of AyurSlim Capsules on the Pharmacodynamics and Pharmacokinetics of Gliclazide in Rats and Rabbits. Int. J. Pharm. Sci. Rev. Res., 26(2): 141-146.

Millat-Martinez P, Bassat Q. 2018. Reappraising the cardio safety of dihydroartemisinin-piperaquine. Lancet Infect. Dis., 3099(18)30360-30368 DOI: 10.1016/S1473-3099(18)30360-8

National Code of Health Research Ethics. 2006. National Health Research Ethics Committee of Nigeria (MHREC) Federal Ministry of Health, Abuja 2006: 1-56.

Park JY, Kim KA, Park PW, Park WC, Shin JG. 2003. Effect of rifampin on the pharmacokinetics and pharmacodynamics of Gliclazide. Clin. Pharmacol. Ther., 74(4): 334-340. DOI: 10.1016/S0009-9236(03)00221-2.

Peron EP, Ogbonna KC, Donohoe KL. 2015. Antidiabetic Medications and Polypharmacy. Clin. Geriatr. Med., 31(1): $17-27 . \quad$ DOI: 10.1016/j.cger.2014.08.017

Pinnamraju J, PV Saranya PV, Rani RK. 2018. A Pattern of Potential Drug-Drug Interactions in Diabetic Foot Ulcer Patients at a Tertiary Care Teaching Hospital. EC Pharmacol. Toxicol., 6(5): 356-364.

Ribeiro da Silva MR, Diniz LM, Ribeiro dos Santos JB, Reis EA, Rodrigues da Mata A, Eloisa de Araújo V, Álvares J, Acurcio F. 2018. Drug utilization and factors associated with polypharmacy in individuals with diabetes mellitus in Minas Gerais, Brazil. Ciênc Saúde Coletiva., 23(8): 2565-2574.

Sandoz Product Monograph PART III: CONSUMER INFORMATION. 2018. 
Sandoz Gliclazide MR.37-40 Sandoz

Canada Inc. (www.sandoz.ca\}

Stachowiak A, Szałek E, Karbownik A, Łojko

A, Porażka J, Przewoźna I, Grabowski T,

Wolc A, Grześkowiak E. 2019. The

influence of diabetes mellitus on glucuronidation and sulphation of paracetamol in patients with febrile neutropenia. Eur. J. Drug Metab. Pharmacokinet., 44: 289-294. DOI: 10.1007/s13318-018-0508-4.

Trinder P. 1969. Determination of blood glucose using an oxidase-peroxidase system with a non-carcinogenic chromogen. J. Clin. Pathol., 22(2): 158161. DOI: http://dx.doi.org/10.1136/jcp.22.2.158

Triplitt C. 2006. Drug Interactions of Medications Commonly Used in Diabetes. Diabetes Spectr., 19(4): 202211.

World Health Organization. 2016. Global Report on Diabetes. Geneva, 2016. Accessed 30 August 2016.
Xu H, Williams KM, Liauw WS, Murray M, Day RO, McLachlan AJ. 2008. Effects of St John's wort and CYP2C9 genotype on the pharmacokinetics and pharmacodynamics of Gliclazide. $B r . J$. Pharmacol., 153: 1579-1586. DOI: 10.1038/sj.bjp.0707685.

Yang F, Xiong X, Liu Y, Hang H, Huang S, Xiong Y, Hu X, Xia. 2018. CYP2C9 and OATP1B1 genetic polymorphisms affect the metabolism and transport of glimepiride and Gliclazide. Sci. Rep., 8(1): $10994 . \quad$ DOI: https://doi.org/10.1038/s41598-01829351-4

Yang JF, Wei GL, Lu R. 2004. Determination of Gliclazide in Human Plasma by HighPerformance liquid chromatography. Asian J. Drug Met. Pharmacol., 4(3): 231-234. 